\title{
Life cycle of Hepatozoon affluomaloti sp. n. (Apicomplexa: Haemogregarinidae) in crag lizards (Sauria: Cordylidae) and in culicine mosquitoes from South Africa
}

\author{
Johann Van As ${ }^{1}$, Angela J. Davies ${ }^{2,3}$ and Nico J. Smit ${ }^{3}$ \\ ${ }^{1}$ Department of Zoology and Entomology, University of the Free State, Phuthaditjaba, South Africa; \\ ${ }^{2}$ School of Life Sciences, Kingston University, Kingston upon Thames, United Kingdom; \\ ${ }^{3}$ Water Research Group (Ecology), Unit for Environmental Sciences and Management, North-West University, Potchefstroom, South \\ Africa
}

\begin{abstract}
A new haemogregarine species Hepatozoon affluomaloti sp. n. is described from erythrocytes in the peripheral blood of crag lizards Pseudocordylus melanotus (Smith) and Pseudocordylus subviridis (Smith) (Sauria: Cordylidae) from mountainous regions in the Eastern Free State, South Africa. This species can be distinguished from all other congeners based on its large size, staining properties and life cycle development in its vector, Culex (Afroculex) lineata (Theobald) (Diptera: Culicidae). Mature gamonts stain mostly uniformly pinkish-purple with Giemsa, sometimes containing darker azurophilic granules anterior and posterior to the nucleus. The reflexed posterior extremity of the gamont stage sometimes stains slightly deeper purple and the nucleus is dense and placed in the posterior third of the parasite body. Merogonic stages of this haemogregarine occur in the liver tissues of $P$. melanotus with dizoic meronts. Macromeronts contains 2-7 macromerozoites and micromeronts contains 9-24 micromerozoites. Sporogonic developmental stages found in the proposed final host and vector, $C$. lineata, include large oocysts, measuring $54 \times 48 \mu \mathrm{m}$ on average. Sporulating oocysts with 8 nuclei are present in mosquitoes $6-7$ days post-feeding on infected lizards. Sporocysts with mature sporozoites measure $31.0 \times 21.8 \mu \mathrm{m}$ on average and each contains $2-8$ large sporozoites. It is suggested that transmission of infective sporozoites is achieved through predation of lizards on mosquitoes.
\end{abstract}

Keywords: gamonts, merogonic stages, oocysts, sporocysts, sporozoites, transmission

Haemogregarines are usually recognised as apicomplexan blood parasites of vertebrates, with heteroxenous life cycles that involve one or more intermediate (vertebrate) hosts and haematophagous invertebrate final hosts (Bashtar et al. 1987, Davies and Johnston 2000, Cook et al. 2009, Telford et al. 2012). Haemogregarines belong to several genera, with more than 30 species of the genus Hepatozoon Miller, 1906 having been described from lizards in Africa (Van As et al. 2013). Species of Hepatozoon are characterised by intraerythrocytic or intraleukocytic gamonts, but division stages are usually lacking in blood films. They also produce macro- and micromeronts typically in vertebrate host liver, and form polysporocystic oocysts in an arthropod invertebrate host (Smith 1996).

Most descriptions of Hepatozoon spp. are based on the morphology of the gamont stages in blood films, but Sloboda et al. (2007) note that descriptions of species, without an account of a corresponding life cycle, are questionable. In particular, little work has been done to identify the final hosts of haemogregarines from lizards, i.e. usually haemat- ophagous arthropods (Al Ghamdi et al. 2011, Telford et al. 2012), or their mode of transmission between hosts (Ball et al. 1967, Levine 1982, Bashtar et al. 1984, Telford et al. 2012). Landau (1973) suggested that transmission of species of Hepatozoon can be achieved by predation and this is likely in the case for the host lizards examined in this paper.

The present study thus provides description of a new species of Hepatozoon based on observation of its life cycle stages in lizards as well as in the invertebrate (final) hosts.

\section{MATERIALS AND METHODS}

\section{Vertebrate host sampling and blood smear preparations}

A total of 98 lizards were collected by hand (Free State Nature Conservation Permit Number: BBB002-00032-0035) during the summer months (September to April), over a period of 5 years (2008-2013). Sixty nine specimens of Pseudocordylus melanotus (Smith) were collected at Platberg reserve (28 14'36.71"S; 
$\left.29^{\circ} 09^{\prime} 45.45^{\prime \prime} \mathrm{E}\right)$ close to the town of Harrismith in the Eastern Free State, South Africa and 29 Pseudocordylus subviridis (Smith) were collected at the Sentinel trail $\left(28^{\circ} 44^{\prime} 41.71 " \mathrm{~S}\right.$; $28^{\circ} 53^{\prime} 05.56 " \mathrm{E}$ ) in the North Eastern Drakensberg (Maloti mountains), Eastern Free State, South Africa.

A drop of peripheral blood was taken from each lizard, by toe clipping, and almost all lizards were released at their site of capture. Blood smears were made on clean microscope slides, air dried, fixed in absolute methanol for 1 minute and stored in dust-free boxes on site. Fixed slides were stained in the laboratory with a $9: 1$ solution of buffered Giemsa (Gurr ${ }^{\circledR}$ Improved R66 solution) for $30 \mathrm{~min}$ and scanned individually for parasites using a Nikon Eclipse photomicroscope (see Van As et al. 2013). Haemogregarine measurements and parasitaemia calculations were performed according to the methods in Van As et al. (2013). All measurements are in micrometres unless otherwise stated.

\section{Maintenance of the vertebrate host, exposure to mosquitoes and subsequent sampling}

One male of $P$. melanotus with a verified infection with the new species of Hepatozoon was kept in a terrarium for one week to acclimatise, provided with laboratory bred mealworms (Coleoptera: Tenebrionidae) and water. The lizard was then placed inside a $40 \times 40 \mathrm{~cm}$ mosquito-rearing cage with newly emerged, uninfected female mosquitoes (see below). After the experiment the lizard was euthanised with $0.5 \mathrm{ml}$ Euthapent (Kryon Laboratories, Johannesburg, South-Africa (edms) bpk) in $1 \mathrm{ml}$ tap water. Heart blood was taken with a micropipette immediately post mortem and small blocks of liver tissue were cut and smeared on clean microscope slides. Liver smears were fixed, stained and examined as for blood films.

\section{Collection and sampling of mosquito hosts}

Females of Culex lineata (Theobald) were collected in the field at night with an aspirator while feeding on P. melanotus that were residing in rock cracks. Engorged female mosquitoes were euthanised in ethyl acetate vapours sequentially from 1 to 30 days post feeding on a laboratory maintained lizard (above). The thorax, head and abdominal contents of the mosquitoes were then squashed between two microscope slides, similar to the methods described in Davies and Smit (2001) and Hayes et al. (2006) for blood-sucking crustaceans. Squashes were then fixed in absolute methanol for $1 \mathrm{~min}$ and stained in a $9: 1$ solution of buffered Giemsa for $30 \mathrm{~min}$ (as for blood films). Stained squash preparations were scanned for possible Hepatozoon developmental stages on a Zeiss stereomicroscope using the $40 \times$ objective. Photographs were taken with a Nikon Coolpix 4500 digital camera custom fitted to a Nikon Eclipse microscope.

\section{Experimental mosquito hosts}

Mosquito eggs and larvae of Culex (Culex) pipiens Linnaeus, Culiseta (Allotheobaldia) longiareolata (Macquart) and Culex andersoni bwambanus Edwards, all identified using the key in Jupp (1996), were collected from freshwater ponds in the town of Harrismith and were fed a $50: 50$ mixture of Nestum ${ }^{\circledR}\left(\right.$ Nestlé $^{\circledR}$, Johannesburg, South Africa) and brewer's yeast (Robertsons ${ }^{\mathbb{B}}$, Cape Town, South Africa). Emerged adult female mosquitoes were kept alive at $25-30{ }^{\circ} \mathrm{C}(50-60 \% \mathrm{RH})$ by feeding with $2 \%$ sucrose solution soaked cotton balls. The insects were then placed in a mosquito-rearing cage with $P$. melanotus specimen infected with the new species of Hepatozoon and were enticed to feed on the lizard by depriving them of the sucrose solution for $24 \mathrm{~h}$.

\section{RESULTS}

Hepatozoon affluomaloti sp. n.

Figs. 1-4

ZooBank number for species:

urn:lsid:zoobank.org:act:FBAC258B-E6E5-

47B4-820C-8EF6BCEE877F

Description of intraerythrocytic gamonts. Giemsastained blood films from Pseudocordylus melanotus, immature gamonts (Fig. 1A, thin arrow) rarely observed, forming parasitaemias of $\sim 1 / 10000(0.01 \%)$ of infected mature erythrocytes, measuring $11.0 \times 3.5(\mathrm{n}=1)$. Maturing or mature intraerythrocytic gamonts (Fig. 1B-D) from peripheral blood broadly elongate, sausage-shaped organisms with reflexed posterior pole (Fig. 1C,D; thin arrows) and broadly rounded, or pointed, anterior extremity (Fig. 1A,D,E-G,I; thick arrows). Infected erythrocytes with two gamonts (Fig. 1D) seen in blood films from one lizard. Gamont anterior pole with cap stained slightly deeper purple than remaining parasite body (Fig. 1D,E,H; thick arrows). Mature gamonts measured 15.8-21.8 (18.7 \pm 1.4$)$ long $\times 3.2-7.3(5.7 \pm 0.9)$ wide $(\mathrm{n}=75)$. Gamont cytoplasm stained mostly uniformly, sometimes with darker azurophilic granules anterior and posterior to nucleus. Reflexed posterior extremity sometimes stained slightly deeper purple (Fig. 1C,D,E,H; thin arrows). Nucleus of gamont dense, placed in posterior third of parasite body, measuring $3.9-7.9(5.8 \pm 1.0) \times 3.0-7.6(5.0 \pm 1.0)(\mathrm{n}=75)$.

Immature gamonts of $H$. affluomaloti sp. n. in blood of Pseudocortylus subviridis rarely observed forming parasitaemias of $\sim 2 / 1000(0.2 \%)$ of mature erythrocytes (Fig. 1K), measuring $\sim 11.0 \times 3.5(\mathrm{n}=2)$. Gamont nuclei, staining dark pink with banded chromatin, covering more than half of parasite body; measuring $\sim 6.0 \times 3.5$ $(\mathrm{n}=2)$. Maturing and mature intraerythrocytic gamonts (Fig. 1L,M) elongated with rounded anterior extremity (Fig. 1M; thin arrow). Anterior pole broader than posterior pole, bearing anterior cap in some individuals (Fig. 1L; thin arrow). Gamonts measuring 17.4-22.0 (19.4 \pm 1.0$) \times$ 5.4-7.6 (6.2 \pm 0.7$)(n=60)$. Cytoplasm stained uniformly pinkish with Giemsa, sometimes with scattered granules anterior and posterior to nucleus. Slightly reflexed posterior end visible in some individuals (Fig. 1L,N, thick arrows). Dense, rounded to oval nucleus stained deep pinkish-purple, containing finely stranded or slightly granular chromatin, centrally or more posteriorly placed (Fig. $1 \mathrm{~L}-\mathrm{N}$ ) in posterior third of parasite body, 5.0-10.1 (6.5 \pm 0.9$)$ long 4.0-6.1 $(5.2 \pm 0.5)$ wide $(n=60)$.

Description of gamonts in heart blood of Pseudocordylus melanotus

Gamonts of intermediate appearance between two types (Fig. 1E-G) observed in heart blood, as well as those identical to those in peripheral blood (Fig. 1H-J). Heart blood gamont stages elongated, with a rounded anterior extremity (Fig. 1F,G). Posterior pole strongly reflexed or sometimes 


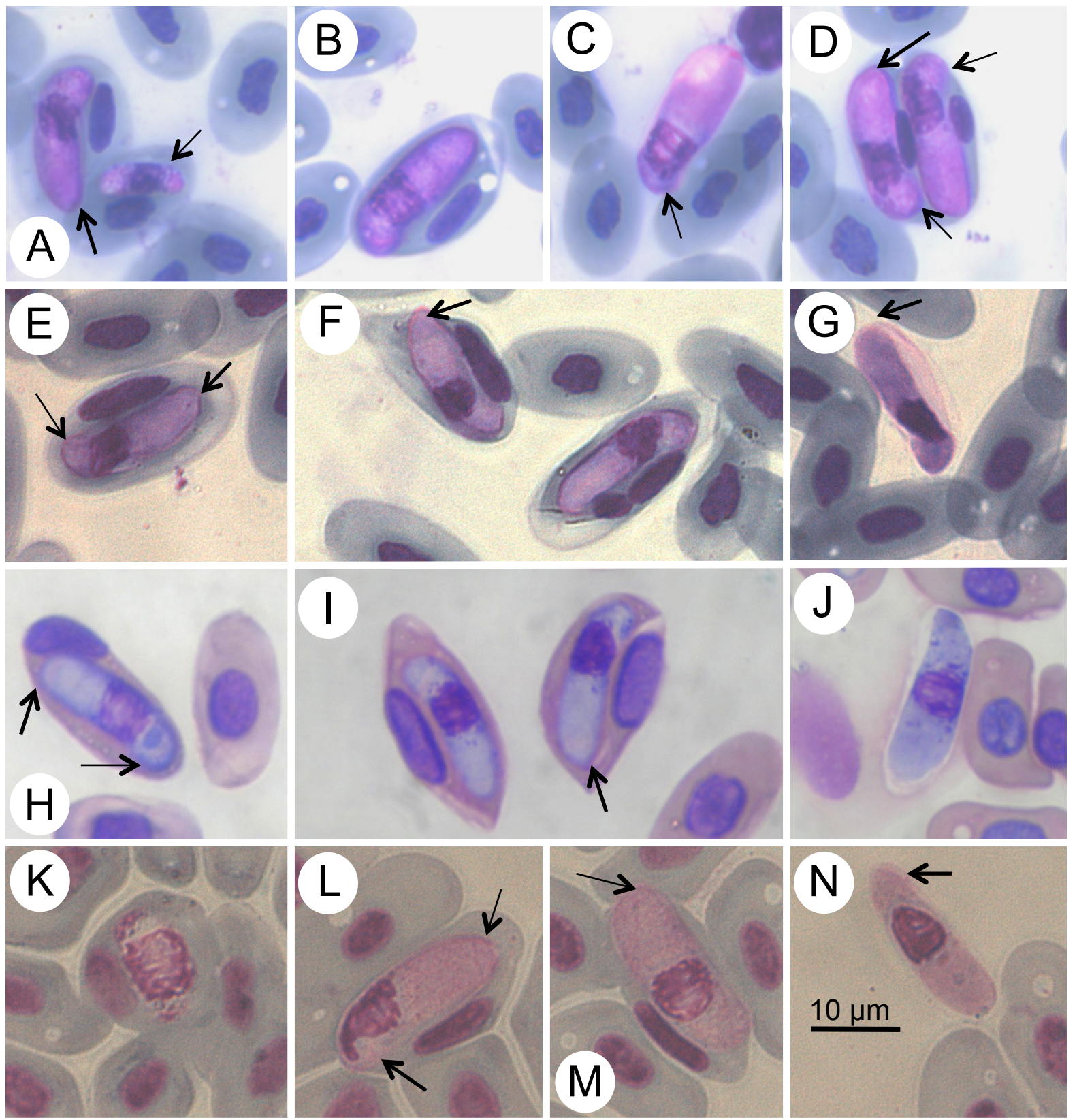

Fig. 1. Micrographs of intraerythrocytic gamont stages of Hepatozoon affluomaloti sp. n. from the peripheral and heart blood of Pseudocordylus melanotus and P. subviridis. A-D - maturing gamonts in the peripheral blood of P. melanotus; $\mathbf{E}-\mathbf{G}-$ gamonts in the heart blood of P. melanotus; $\mathbf{H}-\mathbf{J}$ - mature gamonts in the peripheral blood of P. melanotus; $\mathbf{K}-\mathbf{N}$ - maturing gamonts in the peripheral blood of P. melanotus. Thick arrows: A,D,E-G,I - showing broadly rounded, or pointed, anterior extremity; D,E,H - deeper staining anterior pole; L,N - reflexed posterior pole. Thin arrows: A - immature gamont; C,D - reflexed posterior pole; C,D,E,H - deeper staining reflexed posterior pole; $\mathrm{M}$ - rounded anterior extremity; $\mathrm{L}$ - anterior cap; $\mathrm{E}$ - curved posterior pole.

curved (Fig. 1E, thin arrow) and occasionally stained darker than remaining cytoplasm of gamont. Host cell nucleus mostly less compacted than in peripheral blood stages, but still displaced laterally (Fig. 1E,F).

Occasionally, host cell nucleus absent from infected erythrocytes. Heart blood gamonts 18.7-21.0 (19.8 \pm 0.9$)$ long 3.1-4.2 $(3.6 \pm 0.5)$ wide $(n=20)$, tended to be longer and narrower than those in peripheral blood. Except at posterior pole, main cytoplasm of heart blood gamonts stained paler than its periphery, sometimes with dark azurophilic granules just anterior and posterior to nucleus (Fig. 1H-J). Dense nucleus stained dark purple-blue, situated centrally or in posterior third of parasite body, 5.7-8.0 (6.5 \pm 0.8$)$ long 2.2-3.8 (2.6 \pm 0.5$)$ wide $(\mathrm{n}=7)$ (Fig. $1 \mathrm{E}-\mathrm{G})$.

\section{Description of merogonic stages in Pseudocordylus} melanotus liver tissue

Other internal organs (spleen, heart, kidneys and intestines) were also examined for merogonic stages, but none were observed. However, these organs are not ruled out as potential areas for development of this parasite as only a single lizard was studied.

Meronts were observed primarily in what were presumed to be hepatocytes or endothelial cells, and in the lizard specimen examined, no other organs harboured meronts. Young 

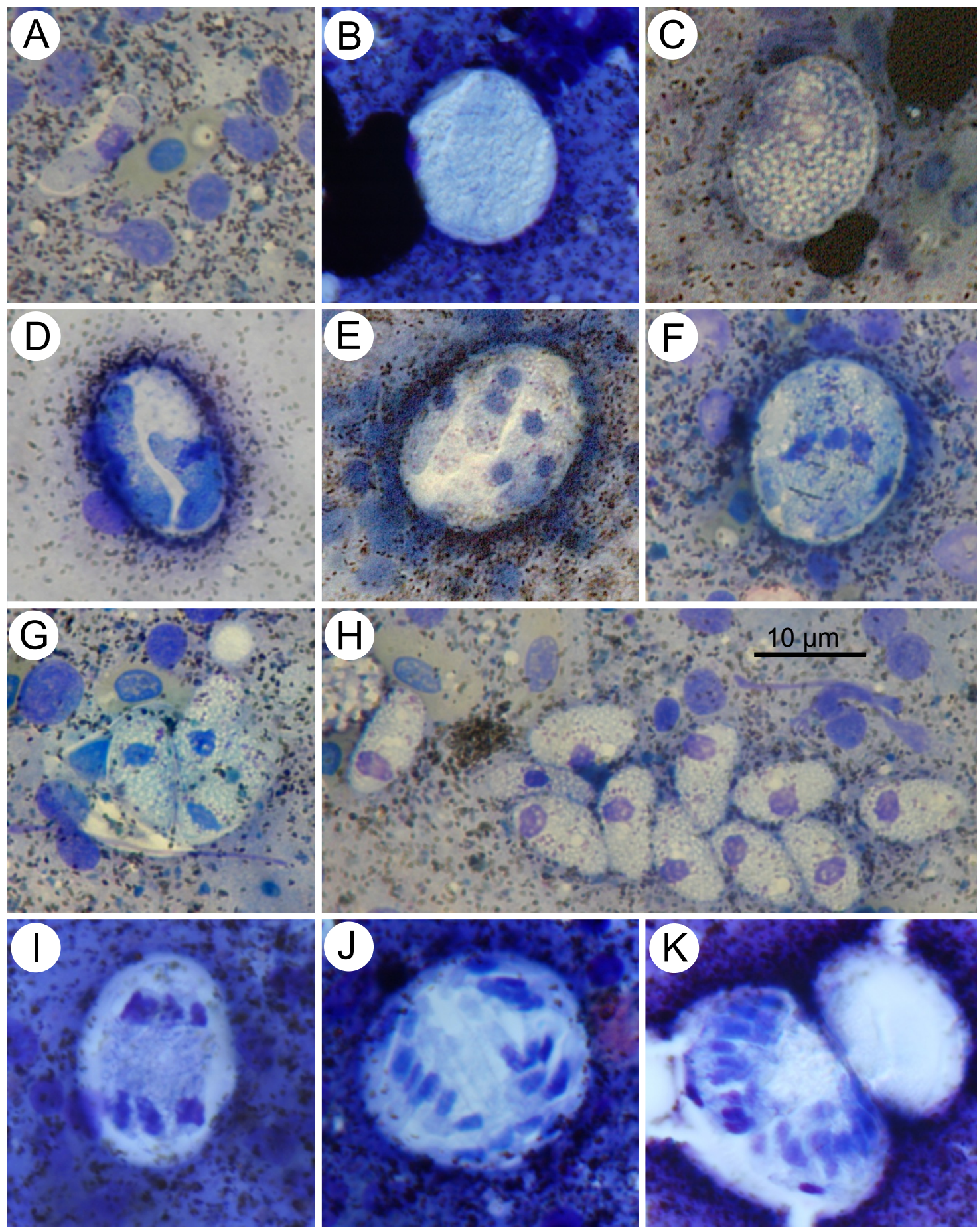

Fig. 2. Micrographs of merogonic developmental stages of Hepatozoon affluomaloti sp. n. in liver tissue of Pseudocordylus melanotus. A - extracellular gamont in liver tissue; B, C - young meronts; D - dizoic meront; E, F - macromeronts with macromerozoites; G, $\mathbf{H}$ - ruptured macromeronts; $\mathbf{I}-\mathbf{K}$ - micromeronts producing 9-24 micromerozoites.

meronts (Fig. 2B,C) presumably arose from sporozoites inoculated by vector and these stages measure 17.0-19.4 $(18.3 \pm 1.0)$ in length by $16.0-18.4(17.1 \pm 1.1)$ in width $(\mathrm{n}=10)$ and apparently contain abundant amylopectin (Fig. 2C). Dizoic meronts (Fig. 2D) rare in liver tissue and measure about $16.8 \times 16.2$. Macromeronts (Fig. 2E,F) most abundant in liver smears measuring 25.9-33.9 (25.6 \pm 2.3$)$ in length by $20.1-26.7(22.7 \pm 2.3) \mu \mathrm{m}$ in width $(\mathrm{n}=10)$, with surface area of $\sim 681.2 \mu \mathrm{m}^{2}$, contating $2-7$ (4 \pm 1.8$)$ $(\mathrm{n}=10)$ macromerozoites.
Individual macromerozoites within macromeronts measuring $15.8-22.4(20.8 \pm 1.8)$ in length by $2.9-8.5$ $(5.2 \pm 1.7)$ in width $(\mathrm{n}=10)$, similar in general morphology to gamont stages in peripheral blood, except that some are more pyriform in shape (Fig. 2E,F).

Macromerozoite cytoplasm stained whitish-blue with dark granules distributed randomly throughout. Nuclear periphery stained dark blue with centre staining dark purple. Macromerozoite nuclei measured 2.8-6.2 (4.0 \pm 1.0$)$ by $1.9-3.1(2.5 \pm 0.4)(\mathrm{n}=10)$. 

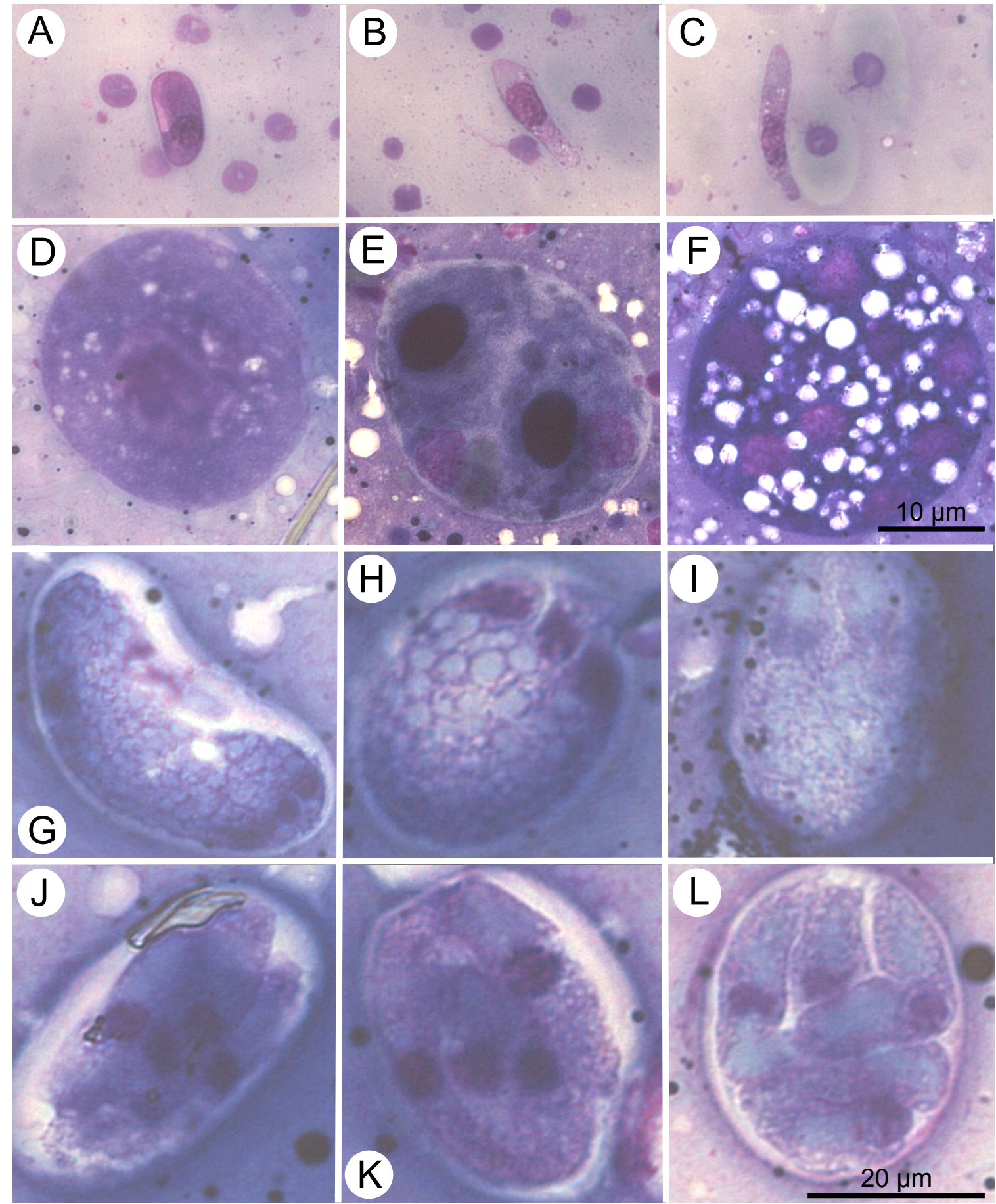

Fig. 3. Photomicrographs of sporogonic stages of Hepatozoon affluomaloti sp. $\mathrm{n}$. in the gut contents of the mosquito Culex (Afroculex) lineata. $\mathbf{A}-\mathbf{C}$ - gamonts from a recent blood meal in the gut contents of mosquito; $\mathbf{D}$ - uninucleate oocyst; $\mathbf{E}$ - binucleate oocyst; $\mathbf{F}$ - sporulating oocyst with 8 nuclei; $\mathbf{G}-\mathbf{I}$ - sporocysts with developing sporozoites; $\mathbf{J}-\mathbf{L}$ - sporocysts containing maturing or mature sporozoites. Scale bar: A-F $=10 \mu \mathrm{m} ; \mathrm{G}-\mathrm{L}=20 \mu \mathrm{m}$.

Ruptured macromeronts (Fig. 2G,H) release macromerozoites foamy in appearance and broader than those within meronts. Extracellular macromerozoites 18.4-22.0 $(19.9 \pm 1.1)$ in length by $7.2-13.0(9.5 \pm 1.3)$ in width $(\mathrm{n}=13)$. Cytoplasm stained light whitish-pink with distinct pink granules distributed around nucleus. Elliptical nuclei (Fig. 2G,H) compact, stained deep purple, 3.6-7.0 $(5.5 \pm 0.8)$ in length by $2.6-6.6(3.6 \pm 1.1)$ in width $(n=13)$.
Micromeronts were also identified in lizard liver (Fig. 2I-K) and were presumed to arise from macromerozoites. Each micromeront produced 9-24 micromerozoites. Micromeronts generally slightly larger than mature macromeronts, $25-40(33 \pm 5.4)$ in length by $30.0-45.0(38.5 \pm 5.3)$ in width $(\mathrm{n}=7)$, with surface area of 402.4-711.4 (506.9 \pm 111.9$) \mu \mathrm{m}^{2}(\mathrm{n}=10)$. Micromerozoites slender and more elongate than macromerozoites 


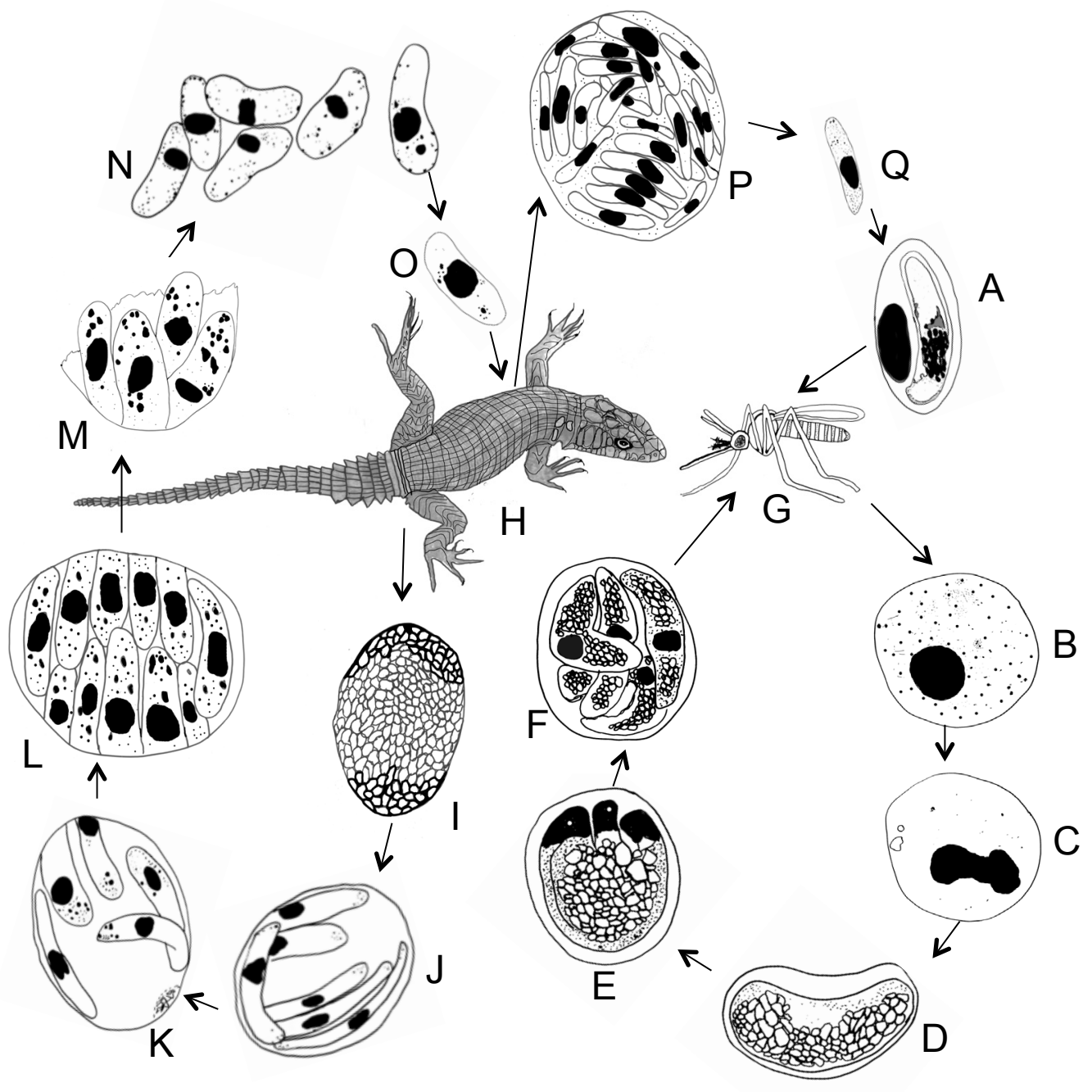

Fig. 4. Diagram representation of the life cycle of Hepatozoon affluomaloti sp. n. A - mature gamonts in the peripheral blood of Pseudocordylus melanotus are taken with a blood meal by female Culex (Afroculex) lineata mosquito; $\mathbf{B}, \mathbf{C}$ - uninucleate and binucleate oocysts developed 3 days post feeding; $\mathbf{D}, \mathbf{E}$ - sporocysts with developing sporozoites; $\mathbf{F}$ - sporocysts, containing maturing or mature sporozoites that resides in the gut contents; $\mathbf{G}$ - female $C$. (A.) lineata mosquito with mature sporozoites are ingested by Pseudocordylus melanotus $(\mathbf{H})$; $\mathbf{I}-\mathbf{L}$ - young meronts in liver tissue of $P$. melanotus development to mature macromeronts with macromerozoites; $\mathbf{M}$ - macromeront ruptures and macromerozoites are released; $\mathbf{N}$ - macromerozoites re-infects the liver $(\mathbf{O})$; $\mathbf{P}$ - mature micromeronts release micromerozoites $(\mathbf{Q})$ that infect erythrocytes.

difficult to measure (none was extracellular) about $18 \times$ 2.5 in size.

Description of sporogonic stages in naturally feeding mosquitoes

In squash preparations made from $C$. lineata 1-7 days post feeding (d.p.f) on infected lizard, haemogregarines and red blood cells (in different stages of digestion) from recent blood meal observed in gut contents (Fig. 3A-C). Morphometrically, ingested gamonts had similar dimensions to gamonts in erythrocytes of host lizard were recognise; two types. Encapsulated form (Fig. 3A) measured $10 \times 2.6(n=1)$. Free gamonts long and slender (Fig. 3B,C), 21.4-28.4 (26.1 \pm 2.1$)$ in length by 3.7-5.6 (4.6 \pm 0.6$)$ in width $(\mathrm{n}=10)$, with nuclei $6.6-13.2(10.0 \pm 1.8)$ in length by $3.1-5.7(4.1 \pm 0.8)$ in width $(\mathrm{n}=10)$. Some free gamonts with broad anterior end(Fig. 3B), 22.9-26.8 (24.3 \pm 1.9$)$ in length by $4.7-6.4(5.4 \pm 0.6)$ in width a $(n=10)$. Nuclei of these broader gamonts $5.7-12.5(9.3 \pm 2.1)$ in length by $3.9-5.3(4.5 \pm 0.6)$ in width $(\mathrm{n}=10)$.
Gametogenesis in naturally infected $C$. lineata and subsequent fertilisation were not seen, but uninucleate and binucleate oocysts (Fig. 3D,E) present 3 d.p.f in the gut contents of mosquitoes measuring $\sim 54 \times 48$ with area of $\sim 2093 \mu \mathrm{m}^{2}$. Nuclei of oocysts measuring $\sim 26.9 \times 25.8$ with area of $\sim 694 \mu \mathrm{m}^{2}$. Six to seven days post feeding sporulating oocysts with 8 nuclei present in gut contents, measuring $\sim 25.5 \times 26.1$ with area of $666 \mu \mathrm{m}^{2}$, likely signalling the onset of sporogony (Fig. 3F), but mature polysporocystic oocysts not observed in these wild-feeding mosquitoes.

Sporocysts with developing sporozoites (Fig. 3G-I) measure 23.0-25.6 $(24.1 \pm 1.1) \times 24.4-28.1(26.1 \pm 1.5)$ $(\mathrm{n}=8)$ with average area of $632 \mu \mathrm{m}^{2}$. Sporocysts containing maturing or mature sporozoites (Fig. 3J-L) 26.7-39.2 $(31.0 \pm 3.8)$ in length by $17.0-25.6(21.8 \pm 0.6)$ in width, contained $2-8(4 \pm 1.4)$ large sporozoites $(n=20)$. Sporozoite cytoplasm with foamy appearance and sporozoites $16.8-32.4(22.4 \pm 4.6)$ in length by $4.0-9.0(5.1 \pm 1.1)$ in width $(\mathrm{n}=18)$. Each sporozoite nucleus rounded and dense 
Table 1. Comparative measurements of surface area, length and width between infected and uninfected erythrocytes and their nuclei.

\begin{tabular}{|c|c|c|c|c|c|c|c|c|}
\hline \multirow[b]{3}{*}{ Host lizards } & \multicolumn{4}{|c|}{ Infected erythrocytes } & \multicolumn{4}{|c|}{ Uninfected erythrocytes } \\
\hline & \multirow{2}{*}{$\begin{array}{c}\text { Erythrocyte } \\
\text { SA }\left(\mu \mathrm{m}^{2}\right)\end{array}$} & \multicolumn{3}{|c|}{ Erythrocyte nuclei } & \multirow{2}{*}{$\begin{array}{c}\text { Erythrocyte } \\
\mathrm{SA}\left(\mu \mathrm{m}^{2}\right)\end{array}$} & \multicolumn{3}{|c|}{ Erythrocyte nuclei } \\
\hline & & length $(\mu \mathrm{m})$ & width $(\mu \mathrm{m})$ & $\mathrm{SA}\left(\mu \mathrm{m}^{2}\right)$ & & length $(\mu \mathrm{m})$ & width $(\mu \mathrm{m})$ & $\mathrm{SA}\left(\mu \mathrm{m}^{2}\right)$ \\
\hline Pseudocordylus melanotus & $\begin{array}{c}161-223 \\
(192 \pm 21)\end{array}$ & $\begin{array}{c}6.4-12.3 \\
(9.1 \pm 1.2)\end{array}$ & $\begin{array}{c}1.9-3.8 \\
(2.9 \pm 0.4)\end{array}$ & $\begin{array}{c}15.5-32.1 \\
(24.5 \pm 4.0)\end{array}$ & $\begin{array}{c}120-192 \\
(139 \pm 24)\end{array}$ & $\begin{array}{c}5.2-7.5 \\
(6.5 \pm 0.6)\end{array}$ & $\begin{array}{c}3.3-4.9 \\
(4.0 \pm 0.6)\end{array}$ & $\begin{array}{c}16.4-26.7 \\
(23.7 \pm 2.6)\end{array}$ \\
\hline Pseudocordylus subviridis & $\begin{array}{c}141-295 \\
(210 \pm 34)\end{array}$ & $\begin{array}{c}6.7-11.0 \\
(8.9 \pm 0.9)\end{array}$ & $\begin{array}{c}2.1-3.7 \\
(2.9 \pm 0.3)\end{array}$ & $\begin{array}{c}18.0-29.6 \\
(23.0 \pm 3.4)\end{array}$ & $\begin{array}{c}122-192 \\
(148 \pm 24)\end{array}$ & $\begin{array}{c}5.2-7.5 \\
(6.5 \pm 0.6)\end{array}$ & $\begin{array}{c}3.3-4.9 \\
(4.0 \pm 0.6)\end{array}$ & $\begin{array}{c}16.0-26.0 \\
(23.9 \pm 2.9)\end{array}$ \\
\hline
\end{tabular}

$\mathrm{SA}$ - surface area.

in appearance, measuring $1.8-5.6(3.4 \pm 1.0)$ by $1.9-4.6$ $(3.3 \pm 0.7)(n=18)$.

Sporogonic stages in experimental mosquitoes (Culex and Culiseta spp.)

Mature gamonts $H$ affluomaloti sp. n. were found in the gut of experimental mosquitoes (Culex Linnaeus and $\mathrm{Cu}$ liseta spp.) one day post feeding on infected P. melanotus. Free gamonts were morphologically and morphometrically similar to those found gut contents of $C$. lineata, 21.4-28.4 $(26.1 \pm 2.1)$ in length by 3.7-5.6 (4.6 \pm 0.6$)$ in width $(\mathrm{n}=10)$. Uninucleate and binucleate oocysts found in gut of Culex pipiens and Culex andersoni Edwards 3 days post feeding. Oocysts measuring $\sim 51 \times 44$ with an area of $\sim 2243 \mu \mathrm{m}^{2}$. Each oocyst nucleus measuring $\sim 7.7 \times 8.2$ with area of $\sim 64 \mu^{2}$. Oocyst-like structures also seen in gut contents of Culiseta longiareolata, they could not be identified with enough certainty to be included in this description. No further sporogonic developmental stages seen in these experimental mosquitoes.

\section{Effects on host erythrocytes}

In general, infected $P$. melanotus erythrocytes stained lighter than non-infected erythrocytes, but were neither hypertrophied nor dehaemoglobulinised. However, in a blood film from one lizard specimen, infected red blood cells were dehaemoglobulinised and a degree of cellular hypertrophy was observed (Fig. 1E-G). The host cell nucleus was usually elongated, compacted and displaced laterally (Fig. 1A,B,E,F,I), sometimes almost terminally (Fig. 1H), and occasionally fragmented (Fig. 1D,F). Parasitised host cell nuclei were larger in length and width and total surface area than uninfected erythrocyte nuclei (Table 1).

Infected erythrocytes in $P$. subviridis were generally not dehaemoglobulinised but were paler stained and bigger than non-infected erythrocytes (see Table 1). The parasitised erythrocyte nucleus was compacted and displaced laterally (Fig. 1M) and was also larger in length, width and surface area (Table 1) than those of uninfected erythrocyte nuclei.

Type host: Pseudocordylus melanotus (Smith) (Sauria: Cordylidae).

Other host: Pseudocordylus subviridis (Smith).

Type 1ocality: Platberg, Eastern Free State, $2101 \mathrm{~m}$.

Other localities: Sentinel area, Northern Drakensberg

(Maloti mountains), Eastern Free State, 2589-3050 m.

Site of infection: Peripheral blood.

Other sites of infection: Liver.
Definitive host: Culex (Afroculex) lineata Theobald.

Other definitive hosts: Culiseta longiareolata (Macquart), Culex pipiens Linnaeus and Culex andersoni Edwards.

Deposition of voucher specimens: Protozoan collection of the National Museum, Bloemfontein, South Africa with numbers NMB P363 (gamonts in the peripheral blood of P. melanotus), NMB P364 (meronts in the liver of P. melanotus) and NMB P365 (sporogonic stages in Culex lineata).

Prevalence: This haemogregarine was found in the peripheral blood of 24/69 (prevalence $35 \%$ ) of P. melanotus sampled at Platberg and in $8 / 29$ (prevalence $28 \%$ ) of $P$. subviridis sampled at Sentinel. The infected $P$. melanotus lizards were 9 females and 15 males; infected $P$. subviridis lizards were 6 males and 2 females. Mature gamonts were the most abundant stages in blood films, although younger gamonts and extracellular forms were also observed on rare occasions. In P. melanotus, Hepatozoon affluomaloti occured simultaneously with other unnamed species of Plasmodium Marchiafava et Celli, 1885, Sauroplasma Du Toit, 1937 and filarial nematode infections (unpublished data). Hepatozoon affluomaloti was seen only in mature erythrocytes in the peripheral blood with parasitaemias ranging from $1 / 1000(0.1 \%)$ to $170 / 1000(17 \%)$; it was also seen in mature erythrocytes in peripheral blood smears of $P$. subviridis and overall parasitaemias ranged from 1/1 000 $(0.1 \%)$ to $18 / 1000(1.8 \%)$ of erythrocytes infected.

E t y m o log y: The species name is derived from a combination of the latin 'affluo' refering to the abundance of this parasite in the Maloti mountains, where it is found.

Remarks. The intraerythrocytic gamonts of H. affluomaloti are larger and wider than $H$. langii Van As, Davies et Smit, 2013 and H. vacuolatus Van As, Davies et Smit, 2013 described in a high altitude cordylid Pseudocordylus langi (Loveridge). Although P. subviridis does occur sympatrically with P. langi at altitudes, their Hepatozoon infections are morphologically and morphometrically distinct. Gamonts of $H$. langii are encapsulated with narrow curved tails and measures $19.1 \times 6.2 \mu \mathrm{m}$ whereas $H$. vacuolatus has distinctive rounded and oval vacuoles and measures $16.5 \times 5.9 \mu \mathrm{m}$. Gamont stages, similar in appearance to those occurring in the peripheral blood, were also observed in squash/smear preparations of $P$. melanotus liver tissue (Fig. 2A) and had presumably escaped the general circulation during tissue preparation. These extracellular gamonts were also morphometrically identical to the blood stream forms in Fig. 1A-J. In liver squash/smear preparations additional haemogregarine stages were observed.

The sporogonic stages of the current species follow the same general pattern as those described by Bashtar et al. (1987) for H. gracilis. Although the dimensions of the 
oocyst stages were not stated by Bashtar et al. (1987), these stages were present in the haemocoel of the experimental mosquito host Culex pipiens molestus on day 5 to 8 post infection. Large oocysts of the new species $(\sim 51 \times 44 \mu \mathrm{m}$ with an area of $\sim 2243 \mu \mathrm{m}^{2}$ ) were seen in squashes of Culex pipiens and $C$. andersoni 3 days post feeding on H. affluomaloti infected blood. Subsequent dissections of these mosquitoes revealed only these oocysts and possible sporocysts, but no sporozoites were seen in these experimental mosquitoes. In wild specimens of Culex lineata collected while feeding on $H$. affluomaloti-infected lizards, oocysts of similar size as in experimental mosquitoes $\left(\sim 54 \times 48 \mu \mathrm{m}\right.$ with an area of $\left.\sim 2093 \mu \mathrm{m}^{2}\right)$ were seen in the gut contents from 1-3 d.p.f. Elliptical sporulating sporocysts and subsequent stages with nuclear division were seen in C. lineata (Fig. 4G). Two C. lineata individuals also revealed sporocysts with developing sporozoites and these sporocysts $(\sim 24 \times 26 \mu \mathrm{m})$ were approximately similar to those of $H$. gracilis $(\sim 22 \times 19 \mu \mathrm{m})$ obtained from C. pipiens molestus.

Hepatozoon affluomaloti apparently differed from H. gracilis by having 2-8 large sporozoites per sporocyst that ranged from $16.8-32.4 \mu \mathrm{m}$ in length by $4-9 \mu \mathrm{m}$ in width, whereas $H$. gracilis produced more sporozoites (8-24) per sporocyst, but these are smaller $\sim 10 \times 2 \mu \mathrm{m}$. When compared to other lizard haemogregarines across Africa, H. affluomaloti overlaps in size with Hepatozoon mabuiae (Nicolle et Comte, 1906) in the scincid lizard, Trachylepis vittata (Oliver, 1804) from Tunisia, which measures 14-17 × 5-6 $\mu \mathrm{m}$ (see Table in Van As et al. 2013). When H. affluomaloti is compared with Hepatozoon gracilis Wenyon, 1909, which was redescribed by Van As et al. (2013) from another skink, Trachylepis quinquetaeniata (Lichtenstein), in the Sudan, gamonts of H. affluomaloti are much broader than those of $H$. gracilis, which are long and slender $(18.0-22.2 \times 0.9-1.4 \mu \mathrm{m})$; both species caused a slight degree of hypertrophy of host erythrocytes and lateral or sometimes terminal, displacement of host cell nuclei.

The merogonic stages of $H$. affluomaloti follow the same overall development pattern as recorded by Wenyon (1909) and Bashtar et al. (1987) for H. gracilis. Wenyon (1909) reported macromeronts with 8-16 macromerozoites in the liver of the lizard and micromeronts with an 'enormous number' of micromerozoites. Bashtar et al. (1987) reported 'micromeronts' that produced 3-16 macromerozoites and 'macromeronts' that produced up to 25-50 micromerozoites. Macromeronts of $H$. affluomaloti in liver tissue produced 2-7 macromerozoites, fewer overall than the macromerozoites from $H$. gracilis.

\section{DISCUSSION}

Hepatozoon affluomaloti sp. $\mathrm{n}$. forms both immature and mature gamonts in the blood of Pseudocordylus melanotus and P. subviridis, but does not apparently divide in the erythrocytes nor causes their lysis. Observations of blood stages using light microscopy indicates, therefore, that it is unlikely a member of the genera Haemogregarina Danilewsky, 1885 or Karyolysus Labbé, 1894. Squash/ smear observations also demonstrate that it forms macro- and micromeronts in lizard liver tissue, suggesting it belongs to the genus Hepatozoon as defined by Smith (1996). The development of $H$. affluomaloti in natural and experimental mosquito hosts reported here further supports its placement in Hepatozoon base on criteria outlined by Smith (1996). Although gametogenesis and fertilisation were not observed in mosquitoes and mature, polysporocystic oocysts were not detected, young oocysts with one, two and multiple nuclei were seen, and numerous sporocysts containing sporozoites were located in naturally infected mosquitoes found feeding on lizards with this haemogregarine.

Stages of $H$. affluomaloti in peripheral blood of $P$. melanotus and P. subviridis are morphologically and morphometrically alike in overall shape, and staining properties and measurements, except for a few additional granules in the cytoplasm of parasites from P. subviridis $($ Fig. $1 \mathrm{~K}-\mathrm{N})$. Infections of $H$. affluomaloti also distorted infected erythrocytes in both lizard species to a similar extent. Therefore, it is assumed that both lizards are infected with the same haemogregarine.

Different variations in the life cycle patterns of Hepatozoon spp. have been reported (for review see Telford 2009). In the majority of species, the appearance of their gamonts in erythrocytes and/or leucocytes of vertebrate hosts, including reptiles, have been reported (Davies and Johnston 2000). Merogony does not usually occur within erythrocytes, but in vascular endothelial cells (Telford 2009). Latent monozoic and dizoic cysts can also exist in vertebrate tissues. In invertebrate hosts such as mites, ticks, insects and possibly leeches, microgametes may be flagellated, but no sporokinetes are formed. In the haemocoel of these same invertebrates, large polycystic oocysts are normally produced with sporocysts containing four to 16 or more sporozoites. Transmission occurs when the vertebrate host ingests the infected invertebrate or through predation on another vertebrate containing tissue cysts (Davies and Johnston 2000).

The range of blood sucking invertebrates that parasitise reptiles includes ixodid and argasid ticks, mites, assassin bugs, dipterans (sandflies, mosquitoes, tsetse flies), anopleurans (sucking lice), siphonapterans (fleas) and hirudineans (leeches) (Smith 1996). Most life cycle studies have been carried out using mosquitoes as possible definitive hosts and Smith (1996) considers Culex, Aedes Meigen and Anopheles Meigen as the main vectors of species of Hepatozoon in ophidians. Low host specificity has been reported from members of this genus. For example Telford et al. (2004) reported Hepatozoon sauritus Telford, Wozniac et Butler, 2001 in four snake species of three genera. Ball (1967) observed in his experiments that Hepatozoon rarefaciens Sambon et Seligmann, 1907 is transferred from a colubrid snake (Drymarchon corais (Boie)) to a boa (Boa constrictor Linnaeus) by means of a mosquito (Culex tarsalis Coquillett). Other authors, e.g. Landau et al. (1970) and Paperna and Lainson (2004), have shown that Hepatozoon host specificity is even lower than that at the level of the first intermediate hosts, and found dizoic, tetrazoic or hexazoic cysts in livers under experimental conditions. 
Wozniak and Telford (1991) successfully transmitted a Hepatozoon species from two species of colubrid snakes, Coluber constrictor Stejneger et Barbour and Nerodia fasciata Linnaeus, to two species of Anolis Daudin. Smith et al. $(1994,1996)$ showed that even amphibians can serve as first intermediate hosts, at least under experimental conditions. Lowichik and Yaeger (1987) demonstrated experimentally using an ovoviviparous snake, Nerodia fasciata, as an experimental host that congenital transmission can represent another route of infection for species of Нераtozoon.

Acknowledgements. This paper is dedicated to the memory of one of the authors (Angela J. Davies), who passed away in December 2013, i.e. in the final phase of the manuscript preparation. The financial assistance of the National Research Foundation (NRF; project IFR2011040100022) is acknowledged. Opinions expressed and conclusions arrived at are those of the authors and are not necessarily to be attributed to the NRF.

\section{REFERENCES}

Al Ghamdi A., Morsy K., Bashtar A.R., Abdel-Ghaffar F., Al-Rasheid K., Al-Quraishy S.,Melhorn H. 2011: Developmental stages of Hepatozoon hemprichii sp. nov. infecting the skink Scincus hemprichii and the tick Hyalomma impeltatum from Saudi Arabia. J. Parasitol. 97: 878-883.

BALL G.H., 1967: Some blood sporozoa from East African reptiles. J. Protozool. 14: 198-210.

Ball G.H., Chao J., Telford S.R. 1967: The life history of Hepatozoon rarefaciens (Sambon and Seligmann, 1907) from Drymarchon corais (Colubridae), and its experimental transfer to Constrictor constrictor (Boidae). J. Parasitol. 53: 897-909.

Bashtar A.R., Abdel-Ghaffar F.A., Melhorn H. 1984: Hepatozoon aegypti nov. sp.: 3. Electron microscopic studies on the gamogony and sporogony inside the vector Culex pipiens molestus. Z. Parasitenkd. 70: 53-65.

Bashtar A.R., Abdel-Ghaffar F.A., Shazly M.A. 1987: Developmental stages of Hepatozoon gracilis (Wenyon, 1909) comb. nov. a parasite of the Egyptian skink, Mabuya quinquetaeniata. Parasitol. Res. 73: 507-514.

Cook C.A., Smit N.J., Davies A.J. 2009: A redescription of Haemogregarina fitzsimonsi Dias, 1953 and some comments on Haemogregarina parvula Dias, 1953 (Adeleorina: Haemogregarinidae) from southern African tortoises (Cryptodira: Testudinidae), with new host data and distribution records. Folia Parasitol. 56: 173-179.

Davies A.J., Johnston M.R.L. 2000: The biology of some intraerythrocytic parasites of fishes, amphibians and reptiles. Adv. Parasitol. 45: 1-107.

Davies A.J., Smit N.J. 2001: The life cycle of Haemogregarina bigemina (Adeleina; Haemogregarinidae) in South African hosts. Folia Parasitol. 48: 169-177.

Hayes P.M., Smit N.J., Seddon A.M., Wertheim D.F., Davies A.J. 2006: A new fish haemogregarine from South Africa and its suspected dual transmission with trypanosomes by a marine leech. Folia Parasitol. 53: 241-248.

JupP P.G. 1996: Mosquitoes of Southern Africa - Culicinae and Toxorhynchitinae. Ekogilde Publishers, Johannesburg, 156 pp.

LANDAU I. 1973: Diversité des mécanismes assurant la pérennité de l'infection chez les sporozoaires coccidiomorphes. Mem. Mus. Nat. Hist. Nat., Nouv. Ser. A 77: 1-62.

Landau I., Chabaud A.G., Michel J.C. 1970: Mise en évidence d'un double mode de transmission chez un Hepatozoon de reptiles malgaches. C. R. Hebd. Séances Acad. Sci., 270: 2308-2310.

Levine N.D. 1982: Apicomplexa. In: S.P. Parker (Ed.), Synopsis and Classification of Living Organisms. McRaw-Hill, New York, pp. 571-587.
Lowichik A., YAeger R.G. 1987: Ecological aspects of snake haemogregarine infections from two habitats in southeastern Louisiana. J. Parasitol. 73: 1109-1115.

Paperna I., Lainson R. 2004: Hepatozoon cf. terzii (Sambon and Selingman, 1907) infection in the snake Boa constrictor constrictor from north Brazil: transmission to the mosquito Culex quinquefasciatus and the lizard Tropidurus torquatus. Parasite 11: $175-181$

Sloboda M., Kamler M., Bulantová J., VotýpKa J., Modrý D. 2007: A new species of Hepatozoon (Apicomplexa: Adeleorina) from Phyton regius (Serpentes: Pythonidae) and its experimental transmission by a mosquito vector. J. Parasitol. 93: $1189-1198$.

Sмiтн T.G. 1996: The genus Hepatozoon (Apicomplexa: Adelina). J. Parasitol. 82: 565-585.

Smith T.G., Desser S.S., Martin D.S. 1994: The development of Hepatozoon sipedon sp. nov. (Apicomplexa: Adeleina: Hepatozoidae) in its natural host, the northern water snake (Nerodia sipedon sipedon), in the culicine vectors Culex pipiens and $C$. territans, and in an intermediate host, the northern leopard frog (Rana pipiens). Parasitol. Res. 80: 559-568.

Sмith T.G., Kopko S.H., Desser S.H. 1996: Life cycles, morphological characteristics, and host specificity of Hepatozoon species infecting eastern garter snake from Ontario. Can. J. Zool. 74: $1850-1856$.

Telford S.R. 2009: Hemoparasites of the Reptilia: Color Atlas and Text. CRC Press, New York, 368 pp.

Telford S.R., Ernst J.A., Clark A.M., Butler J.F. 2004: Hepatozoon sauritus: a polytopic hemogregarine of three genera and four species of snakes in northern Florida, with specific identity verified from genome analysis. J. Parasitol. 90: 352-358.

Telford S.R., Moler P.E., Butler J.F. 2012: Four additional Hepatozoon species (Apicomplexa: Hepatozoidae) from north Florida rat snakes, genus Pantherophis. Folia Parasitol. 59: $167-172$.

Van As J., Davies A.J., Smit N.J. 2013: Hepatozoon langii n. sp. and Hepatozoon vacuolatus n. sp. (Apicomplexa: Adeleorina: Hepatozoidae) from the crag lizard (Sauria: Cordylidae) Pseudocordylus langi from the North Eastern Drakensberg escarpment, Eastern Free State, South Africa. Zootaxa 3608: 345-356.

WENYON C.M. 1909: Report of travelling parasitologist and protozoologist. Wellcome Tropical Research Laboratories (Khartoum) 3: $121-168$.

WozniaK E.J., Telford S.R. 1991: The fate of possibly two Hepatozoon species naturally infecting Florida black racers and watersnakes in potential mosquito and soft tick vectors: histological evidence of pathogenicity in unnatural host species. Int. J. Parasitol. 21: 511-516.

Cite this article as: Van As J., Davies A.J., Smit N.J. 2015: Life cycle of Hepatozoon affluomaloti sp. n. (Apicomplexa: Haemogregarinidae) in crag lizards (Sauria: Cordylidae) and in culicine mosquitoes from South Africa. Folia Parasitol. $62: 008$. 